\title{
Outcome of ATP-based tumor chemosensitivity assay directed chemotherapy in heavily pre-treated recurrent ovarian carcinoma
} Sanjay Sharma*1,5, Michael H Neale ${ }^{1}$, Federica Di Nicolantonio ${ }^{1}$, Louise A Knight $^{1}$, Pauline A Whitehouse ${ }^{1}$, Stuart J Mercer ${ }^{1}$, Bernard R Higgins ${ }^{1}$, Alan Lamont ${ }^{1}$, Richard Osborne ${ }^{3}$, Andrew C Hindley ${ }^{4}$, Christian M Kurbacher ${ }^{2}$ and Ian A Cree ${ }^{1}$

\author{
Address: ${ }^{1}$ Translational Oncology Research Centre, Queen Alexandra Hospital, Portsmouth, UK, ${ }^{2}$ Laboratory for Chemosensitivity Testing, \\ Department of Gynaecology, University of Cologne, Germany, ${ }^{3}$ Dorset Cancer Centre, Poole, Dorset, UK, ${ }^{4}$ Rosemere Cancer Centre, Royal Preston \\ Hospital, Preston, UK and ${ }^{5}$ The King Edward VII Hospital, Midhurst, UK \\ Email: Sanjay Sharma* - sanjay.sharma@porthosp.nhs.uk; Michael H Neale - mneale_75@yahoo.co.uk; Federica Di \\ Nicolantonio - federica.dinicolantonio@porthosp.nhs.uk; Louise A Knight - louise.knight@porthosp.nhs.uk; \\ Pauline A Whitehouse - pauline.whitehouse@porthosp.nhs.uk; Stuart J Mercer - mercersurgeon@ @otmail.com; \\ Bernard R Higgins - bernie.higgins@port.ac.uk; Alan Lamont - alan.lamont@southend.nhs.uk; Richard Osborne - rjosborne@csi.com; \\ Andrew C Hindley - Andrew.Hindley@lthtr.nhs.uk; Christian M Kurbacher - christian.kurbacher@medizin.uni-koeln.de; \\ Ian A Cree - ian.cree@porthosp.nhs.uk \\ * Corresponding author
}

This article is available from: http://www.biomedcentral.com/I47I-2407/3/19

(c) 2003 Sharma et al; licensee BioMed Central Ltd. This is an Open Access article: verbatim copying and redistribution of this article are permitted in all media for any purpose, provided this notice is preserved along with the article's original URL.

\begin{abstract}
Background: We wished to evaluate the clinical response following ATP-Tumor Chemosensitivity Assay (ATP-TCA) directed salvage chemotherapy in a series of UK patients with advanced ovarian cancer. The results are compared with that of a similar assay used in a different country in terms of evaluability and clinical endpoints.

Methods: From November 1998 to November 200I, 46 patients with pre-treated, advanced ovarian cancer were given a total of 56 courses of chemotherapy based on in-vitro ATP-TCA responses obtained from fresh tumor samples or ascites. Forty-four patients were evaluable for results. Of these, 18 patients had clinically platinum resistant disease (relapse $<6$ months after first course of chemotherapy). There was evidence of cisplatin resistance in 31 patients from their first ATP-TCA. Response to treatment was assessed by radiology, clinical assessment and tumor marker level (CA 125).

Results: The overall response rate was 59\% (33/56) per course of chemotherapy, including 12 complete responses, 21 partial responses, 6 with stable disease, and 15 with progressive disease. Two patients were not evaluable for response having received just one cycle of chemotherapy: if these were excluded the response rate is $61 \%$. Fifteen patients are still alive. Median progression free survival (PFS) was 6.6 months per course of chemotherapy; median overall survival (OAS) for each patient following the start of TCA-directed therapy was 10.4 months $(95 \%$ confidence interval 7.9-12.8 months).
\end{abstract}


Conclusion: The results show similar response rates to previous studies using ATP-TCA directed therapy in recurrent ovarian cancer. The assay shows high evaluability and this study adds weight to the reproducibility of results from different centres.

\section{Background}

Despite surgical refinements and the introduction of landmark chemotherapy agents such as cisplatin in the 1970's and paclitaxel in the 1990's, improvements in the overall survival of epithelial ovarian cancer have only been modest [1]. The currently accepted first line treatment is cis- or carboplatin with the addition of a taxane and this is now the most commonly employed control arm in randomised trials $[2,3]$. This together with surgery can result in response rates of $70-80 \%$. However, most of these patients will relapse between one to two years and only $20-30 \%$ will be alive after 5 years with a median overall survival of 35 months [2,3].

The optimal treatment of recurrent disease is unclear and a number of different drugs are used. The response rate to second line treatment depends on the prevalence of platinum resistance at that time [4-7]. The length of the disease free interval categorises patients into platinumsensitive (those progressing 6 months or more after completion of first line platinum agents) and platinum refractory (those progressing on or within 6 months after completion of first line platinum agents). Several different chemotherapy agents have shown some activity in patients with recurrent disease but response rates are still under $30 \%$ in unselected groups [8]. However, there is evidence of heterogeneity of chemosensitivity and patients may benefit from a change of treatment if they progress on the first drug selected. There are no phase III randomized trial-based data to suggest that combination chemotherapy is any better than single agent chemotherapy, though recent phase II trials suggest that combinations may be useful, at least in patients relapsing after more than six months off first-line treatment $[9,10]$.

Selection of the optimal salvage chemotherapy by a laboratory test would in theory allow individualisation of treatment. However, this requires a standardised, evaluable assay technique. The ATP tumor chemosensitivity assay (ATP-TCA) described here is a new generation assay. Previous chemosensitivity assays have been dogged by technical difficulties over the past 25 years $[11,12]$, though several have shown potential in clinical trials [13]. The ATP-TCA compares favourably with all previous methods in terms of standardisation, evaluability, tumor cell number required, reproducibility and accuracy. [1315] It is possible to test cells from needle biopsies and malignant effusions as well as solid tumor biopsies. The high sensitivity of the ATP-TCA requires only $1 \times 10^{6}$ tumor cells to test 4-6 drug regimens. Encouraging correlations between assay results and clinical outcome have been reported [16], and use of the assay in one centre (University of Köln, Köln, Germany) for patients with recurrent ovarian cancer produced a $64 \%$ response rate with improved progression-free survival [17].

Here we present the results of ATP-TCA directed therapy in multiple centres using 56 human epithelial ovarian cancer specimens from 46 patients previously treated with chemotherapy, 8 of whom received multiple ATP-TCA directed therapies. We report on the objective response rate (ORR), progression free survival (PFS) and the overall survival (OAS) and discuss the results in relation to similar ATP assays carried out in different centres.

\section{Patients and methods \\ Patients and treatment}

From October 1998 to November 2001 forty-six patients with histologically proven recurrent ovarian carcinoma were treated prospectively with ATP-TCA directed chemotherapy regimens. Patient characteristics are summarised in Table 1. Written informed consent was obtained from all patients. tumor specimens were obtained either at laparotomy, laparoscopy or paracentesis of a malignant ascites or effusion. Specimens were placed into sterile containers containing a basic transport medium (DMEM, Sigma-Aldrich, Poole, Dorset UK) with penicillin, streptomycin and gentamicin as additives. Ascites containers also contained heparin sulphate 5000 i.u. These were immediately packed into chilled polystyrene containers and transported by courier to arrive in the laboratory (Queen Alexandra Hospital, Portsmouth) within 24 hours. All specimens were confirmed for malignancy by histology or cytology.

Patients were treated with the optimal protocol as indicated by the ATP-TCA assay. This was the regimen with the highest ex-vivo activity that could be tolerated by the patient concerned, taking into account the likely toxicity profile of the drugs selected. Combination therapies had to demonstrate considerable activity over the best single agent tested if they were to be selected. Any supportive treatment needed was freely instituted when need arose during therapy.

The only eligibility criteria were relapsed epithelial ovarian cancer previously treated with chemotherapy and fitness to receive further chemotherapy. Relapse was defined 
Table I:

\begin{tabular}{lr}
\hline PATIENT CHARACTERISTICS & N = 46 \\
\hline Median age (range) & $55(33-76)$ \\
Median performance status (range) & $2(0-4)$ \\
Median number of prior chemotherapies (range) & $2(1-5)$ \\
\hline Summary of prior chemotherapy & No. Patients \\
Number of treatments prior to ATP-TCA & $13(28 \%)$ \\
1 & $18(39 \%)$ \\
2 & $10(22 \%)$ \\
4 & $4(9 \%)$ \\
5 & $1(2 \%)$ \\
\hline FIGO stage (No.) & $40(87 \%)$ \\
Illc & $6(13 \%)$ \\
IV & $6(13 \%)$ \\
Patients with non-serous histology & $18(39 \%)$ \\
Platinum-refractory patients* & $33(72 \%)$ \\
Patients with a Cisplatin Index $>350$ on first ATP-TCA & $37(80 \%)$ \\
\hline
\end{tabular}

*Defined as relapse $<6$ months after completion of first course of platinum containing chemotherapy

as occurrence of malignant pleural effusion or ascites (substantiated by positive cytology), a CA125 of over 70 $\mathrm{U} / \mathrm{mL}$ which had at least doubled from the previous value (samples taken $\geq 28$ days apart) [18] or radiographically measurable disease with $>20 \%$ increase in the sum of the longest diameter of target lesions. Patients of any WHO performance status thought fit enough by their oncologist to withstand chemotherapy were included in this series, irrespective of marrow, renal or hepatic function.

Therapy was monitored using clinical, biochemical and radiological parameters. Where possible CA125 measurements were taken before treatment and monthly thereafter in order to monitor response. Physical examination was carried out monthly. tumor imaging was performed routinely after 3 cycles or earlier to establish progressive disease. Patient response to treatment was assessed by clinical and radiological means according to RECIST criteria as complete response (CR), partial response (PR), stable disease (SD) or progressive disease (PD) [19]. The ORR was defined as the sum of CR and PR. A falling CA125 without a clinical or radiological correlate did not qualify a patient for a CR or PR.

Patients were regarded as evaluable if a minimum of 2 cycles of chemotherapy were administered. All chemotherapy was continued for a minimum of 4 cycles in responders and in patients experiencing stable disease. All patients were followed up routinely on a three monthly basis with clinical examination and CA125 levels. Addi- tional imaging was performed as indicated. On relapse of disease, if further treatment was offered, this was either physician's choice or a further course of ATP-TCA directed therapy. Patients were defined as platinum-refractory if they showed progression of disease during or within 6 months after completion of platinum-based chemotherapy $[6,20,21]$

\section{ATP chemosensitivity testing}

The ATP-TCA methodology has been previously described in detail $[14,22]$. Briefly, specimens were obtained at surgery or from malignant effusions. tumor cells were isolated by enzymatic dissociation using Collagenase Type $\mathrm{H}$ (Sigma-Aldrich, Poole, Dorset, UK) at a concentration of $0.75 \mathrm{mg} / \mathrm{mL}$ for 12 hours. Cell viability was expressed as a percentage using a counting chamber and the total viable cell count used to calculate final working volumes. The tumor cells were then seeded into each well of a 96-well polypropylene microplate using 20,000 cells per well for solid tumors and 10,000 cells per well for ascites samples. These were tested with a maximum of 14 different single agent and combination chemotherapy agents. Drugs were added to the wells prior to seeding and there was no preincubation period for the cells. These included standard and experimental combinations (Table 2).

Each single agent or combination was tested at six doubling dilutions $(6.25 \%$ to $200 \%)$ of test drug concentrations (TDC) derived from pharmacokinetic data, including the degree of protein binding. The assay is 
Table 2: Chemotherapy Regimens Used

\begin{tabular}{|c|c|c|}
\hline Regimen & $\begin{array}{l}\text { Number of patient treatments } \\
\qquad(N=56)\end{array}$ & Protocol \\
\hline Carboplatin & 1 & 5(GFR+25)mg;6 cycles; q3 wk \\
\hline Mitoxantrone & 1 & $12 \mathrm{mg} / \mathrm{m}^{2} ; \mathrm{q}^{3} \mathrm{wk}$ \\
\hline Treosulfan & 1 & 7000 mg/m²; q4 wk \\
\hline Gemcitabine & I & 1250 mg/m²; dl,8; q3 wk \\
\hline Treosulfan and gemcitabine & 23 & $5000 \mathrm{mg} / \mathrm{m}^{2} ; \mathrm{dl} \& 1000 \mathrm{mg} / \mathrm{m}^{2} ; \mathrm{dl} ; \mathrm{q}^{3}$ wk \\
\hline Liposomal Doxorubicin $\left(\right.$ Caelyx ${ }^{\circledR} /$ Doxil $\left.^{\circledR}\right)$ & 8 & $40 \mathrm{mg} / \mathrm{m}^{2} ; \mathrm{dl} ; \mathrm{q} 3 \mathrm{wk}$ \\
\hline Mitoxantrone and paclitaxel & 8 & $4 \mathrm{mg} / \mathrm{m}^{2} ; \mathrm{dl}, 2 \& 175 \mathrm{mg} / \mathrm{m}^{2} ; \mathrm{d} 3 ; \mathrm{q}^{3} \mathrm{wk}$ \\
\hline Cisplatin and gemcitabine & 5 & $75 \mathrm{mg} / \mathrm{m}^{2} ; \mathrm{dl} \& 1250 \mathrm{mg} / \mathrm{m}^{2} ; \mathrm{dl}, 8 ; \mathrm{q} 3 \mathrm{wk}$ \\
\hline Mitoxantrone and gemcitabine & 1 & $12 \mathrm{mg} / \mathrm{m}^{2} ; \mathrm{dl}, 2 \mathrm{I} \& 1000 \mathrm{mg} / \mathrm{m}^{2} ; \mathrm{dl} ; \mathrm{q} 3 \mathrm{wk}$ \\
\hline Liposomal Doxorubicin and gemcitabine & i & $45 \mathrm{mg} / \mathrm{m}^{2} ; \mathrm{dl} \& 500 \mathrm{mg} / \mathrm{m}^{2} ; \mathrm{dl}, 8 ; \mathrm{q} 3 \mathrm{wk}$ \\
\hline Epirubicin and treosulfan & 2 & $60 \mathrm{mg} / \mathrm{m}^{2} ; \mathrm{dl} \& 5000 \mathrm{mg} / \mathrm{m}^{2} ; \mathrm{dl} ; \mathrm{q} 4 \mathrm{wk}$ \\
\hline Vinorelbine and Liposomal Doxorubicin & 2 & $15 \mathrm{mg} / \mathrm{m}^{2} \& 30 \mathrm{mg} / \mathrm{m}^{2} ; \mathrm{q}^{3} \mathrm{wk}$ \\
\hline Epirubicin and paclitaxel & 2 & $25 \mathrm{mg} / \mathrm{m}^{2} ; \mathrm{dI}, 2 \& 175 \mathrm{mg} / \mathrm{m}^{2} ; \mathrm{d} 3 ; \mathrm{q} 3 \mathrm{wk}$ \\
\hline
\end{tabular}

carried out in triplicate wells with positive and negative controls using a serum-free medium (CAM, DCS Innovative Diagnostik Systeme, Hamburg, Germany). The ATP content of each well was measured after 6 days incubation (5\% $\mathrm{CO}_{2}, 37^{\circ} \mathrm{C}$ and $100 \%$ humidity) by the addition of luciferin-luciferase to an aliquot of the lysed cells in a luminometer (MPLX, Berthold Diagnostic Systems, Hamburg, Germany) and analysed with custom software to provide both numerical and graphical results. Luminescence measurements are directly related to ATP levels and allow measurement of the percentage inhibition by reference to untreated control wells included with each plate $[14,15]$.

The results are interpreted and compared using four parameters. The drug concentrations that achieve 50 and/ or $90 \%$ growth inhibition (IC50 and IC90 respectively) are calculated by interpolation. A sensitivity index (Index SUM) is calculated as the sum of the percentage inhibition at each concentration tested (SI $=600-\Sigma \%$ Inhibition at $200,100,50,25,12.5$ and $6.25 \%$ TDC). Lastly, the area under the dose-response curve (Index AUC) is calculated using the trapezoidal rule. Previous studies have shown the Index SUM to be superior to the Index AUC and IC50 for determination of sensitivity and resistance as this relates more closely to the shape of the concentrationinhibition curve [16]. Definitions of sensitivity and resistance for Index SUM and Index AUC were calculated by log-rank tests referring to PFS and OAS [14]. In this study an Index SUM > 350 was taken to indicate probable resistance. Drugs were classified into three groups (probably sensitivity, equivocal sensitivity and probable resistance) on the basis of IndexSUM, and clear evidence of a concentration-response curve with at least 95\% inhibition at $100 \%$ TDC. Synergism or additive effects for individual patients were not routinely assessed. A report was gener- ated including the interpretation of the data, the concentration-inhibition graphs and the derived parameters (IndexSUM, IndexAUC, IC90 and IC50). This report was sent to the oncologist in charge of the patient who decided the treatment according to the assay results and previous toxicity data from the patient concerned. In all cases, patients were treated with drugs shown to be active in the assay.

\section{Statistics}

The results of this non-comparative study are presented with descriptive statistics based on an intention to treat analysis. All data was collected retrospectively by scrutiny of case notes and investigational results. Clinical details were collected blind to the assay results. PFS and OAS were measured from the first day of ATP-TCA directed chemotherapy. OAS has not been corrected for cause of death, which has been considered to be due to ovarian cancer. Autopsies were not performed on these patients. Descriptive statistics are used to describe patient demographic and disease characteristics. Kaplan-Meier survival methods were used to summarize the time-to event variables of time to progression and overall survival.

\section{Results}

A total of 46 patients underwent 56 courses of ATP-TCA directed chemotherapy. Two patients received only one cycle of assay directed therapy and then withdrew from treatment. Second look laparotomies were not performed, but 9 patients had tissue samples taken at diagnostic laparoscopy. None of the patients had further tumor debulking surgery.

The treatments given are summarised in Table 2. Drug combinations were given on 44 (79\%) occasions and of these 30 (54\%) were non-standard protocols. 
Table 3: Results of chemotherapy

\begin{tabular}{lll}
\hline No. of patients & 46 & \\
No. ATP-TCA directed courses & 56 & $(21 \%)$ \\
CR & 12 & $(38 \%)$ \\
PR & 21 & $(11 \%)$ \\
SD & 6 & $(27 \%)$ \\
PD & 15 & $(4 \%)$ \\
No. of patients not evaluable for response & 2 & $(59 \%)$ \\
ORR & 33 & \\
Median PFS (months) & 6.6 & \\
Median OAS (months) & 10.4 & \\
\hline
\end{tabular}

\section{Response}

Of the 54 ATP-TCA directed chemotherapies evaluable for response, there were 12 complete responses (CR), 21 partial responses (PR), 6 stable disease (SD) and 15 with progressive disease (PD). Two patients were not evaluable for response (withdrew after one cycle of treatment). Of the 44 patients treated, 15 are still alive at the date of analysis (3 CR, 9 PR, 2 SD and 1 PD). For evaluable patients, the ORR was $61 \%$ per course of ATP-TCA directed chemotherapy (12 CR and 21 PR). By intention-to-treat (ITT) analysis, the response rate was $59 \%$, including the two patients who received just one cycle of chemotherapy and were not evaluable. The results of chemotherapy are summarised in Table 3.

Eight patients had more than one course of ATP-TCA directed chemotherapy (range 2-4 courses). Four of these responded to two or more courses of ATP-TCA directed chemotherapy. One patient responded to three successive courses and 3 of these patients are still alive at the time of analysis. The median OAS for these patients was 13.7 months (Anderson 95\% CI 11.5-15.9 months) from the start of ATP-TCA directed therapy.

Of the clinically platinum-resistant patients (18), there were 3CR, 8 PR, 4 SD, 3 PD with a 61\% ORR. Of platinum-sensitive patients (26), there were $8 \mathrm{CR}, 9 \mathrm{PR}, 2 \mathrm{SD}$, 7 PD with a $65 \%$ ORR. Of 54 ATP-TCAs, 52 were evaluable for cisplatin sensitivity. Analysis of patients grouped by Index SUM for cisplatin sensitivity showed $72 \%$ of patients to be resistant to cisplatin in the assay. The ORR of patients with a cisplatin sensitivity index $>350$ and $<350$ was $58 \%(\mathrm{~N}=38)$ and $75 \%(\mathrm{~N}=12)$ respectively.

\section{Survival}

The median PFS for all 56 patients was 6.6 months (Anderson 95\% CI 3.6-9.6 months) and the median OAS 10.4 months (Anderson 95\% CI 7.9-12.8 months). Figure 1 illustrates progression free survival and figure 2 illustrates overall survival for the group calculated by KaplanMeier statistics.

\section{Discussion}

The $59 \%$ response rate (61\% for evaluable patients) supports data from previous work using the ATP-TCA in another centre [17]. All patients had stage IIIc or IV disease and the inclusive criteria for treatment (with regard to performance status, laboratory criteria and previous toxicity) allowed the inclusion of patients who were clinically unwell as a result of their disease or otherwise. It is reasonable to assume that the outcomes for this group are likely to be less favourable than generally quoted figures.

The use of antineoplastic agents in third line and subsequent therapy has been questioned since the objective response rate is so low in women failing previous therapy. In the UK, most patients with relapse after second line chemotherapy are referred for palliative care [23]. It has also been suggested that potentially useful new agents should not be evaluated in multiple treated patient populations as they risk being labelled "inactive" [24]. However, we know that women may survive for months and even years after failing initial therapy and that they may respond several more times to chemotherapy regimes, particularly in the platinum-sensitive group $[25,26]$. A recent study showed that compared to non-cancer controls, women with recurrent ovarian cancer overwhelmingly preferred salvage therapy to palliation. Quality of life was of secondary importance to the desire to continue aggressive treatment [27]. However, the choice of third, fourth or even fifth line therapy is difficult. Previous trials of chemotherapy in recurrent ovarian cancer have documented response rates between $13-50 \%$ and this includes trials of second-line therapy and patients with stage I and II disease [28-35] There are few randomised trials and none have demonstrated a clear benefit for one regimen over another. Clinical activity has been demonstrated with agents such as pegylated liposomal doxorubicin [29,33], topotecan [28,30,32], altretamine [34], gemcitabine [36] and etoposide [37]. The heterogeneity of response to treatment in recurrent ovarian cancer makes choice of treatment difficult. 


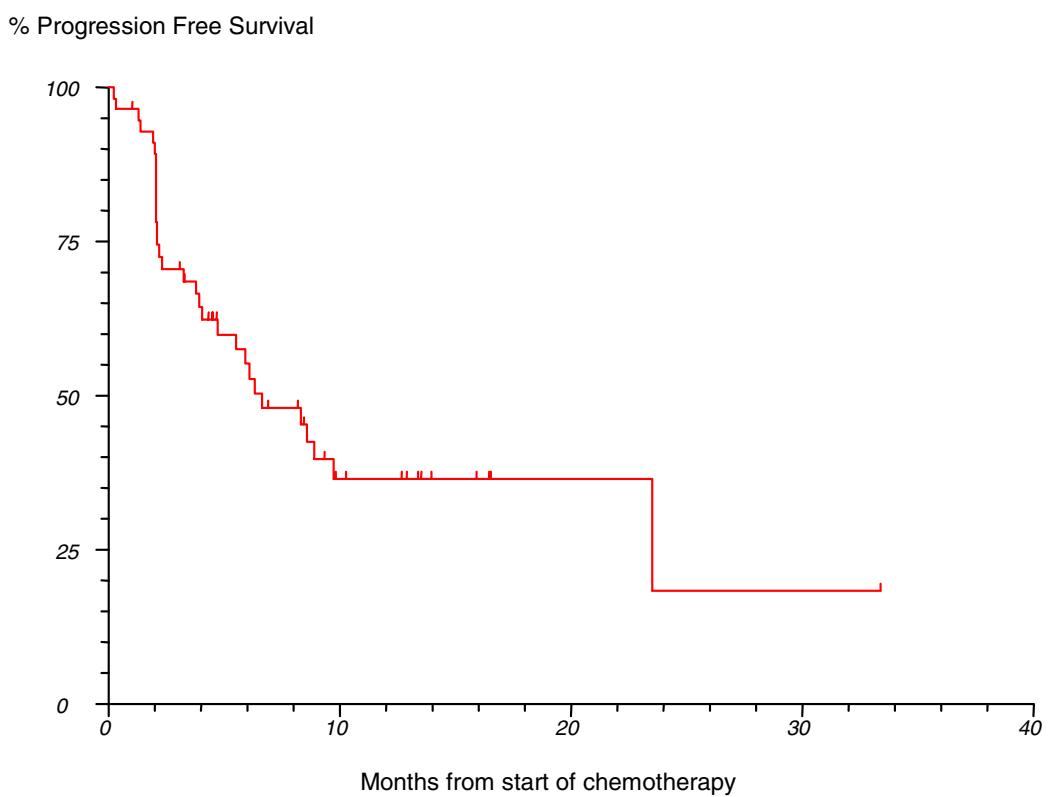

Figure I

PFS following assay-directed chemotherapy.

There are no data conclusively proving combination therapy is superior to single-agent therapy in relapsed disease. Increased activity with some combinations has been shown in randomised trials, but often in selected groups and it is not certain that the benefit will translate into improved survival [38]. Two studies have recently shown impressive response rates using weekly cisplatin and oral etoposide [9,10]. Van der Burg et al. [10] used a different definition of platinum sensitivity to Meyer et al. [9], favouring the 1998 consensus classification [39]. This grouped patients into platinum refractory, platinum intermediate-sensitive and platinum sensitive based on their treatment free interval since last platinum containing therapy (i.e. $<4$ months, 4-12 months and >12 months, respectively). The response rates were $46 \%, 91 \%$ and $92 \%$ in the refractory, intermediate and sensitive groups respectively. However, the patient sample differed considerably from ours in that $90 \%$ of the patient sample had a WHO performance status of 0 or 1 and $74 \%$ had only one prior chemotherapy regimen. Survival was not calculated on an intention to treat analysis. We believe our group of patients is more representative of the everyday clinic situation, were of a poorer prognostic group (median WHO performance status of 2 and $80 \%$ of patients with ascites), and have shown benefit from the use of the ATP-TCA.

Meyer et al. [9] used a relapse cut-off of six months to define platinum sensitive patients. Using CA125 criteria to assess response they found that $46 \%$ of platinum resistant patients responded to this regimen (median survival 6.3 months). The response rate in the platinum sensitive group was slightly less (43\%). This is surprising and very different from the results published by van der Burg et al. [10] We used the same definition of platinum sensitivity as Meyer et al. [9] and have also seen a similar ORR (61\% and $65 \%$ for platinum resistant and platinum sensitive 


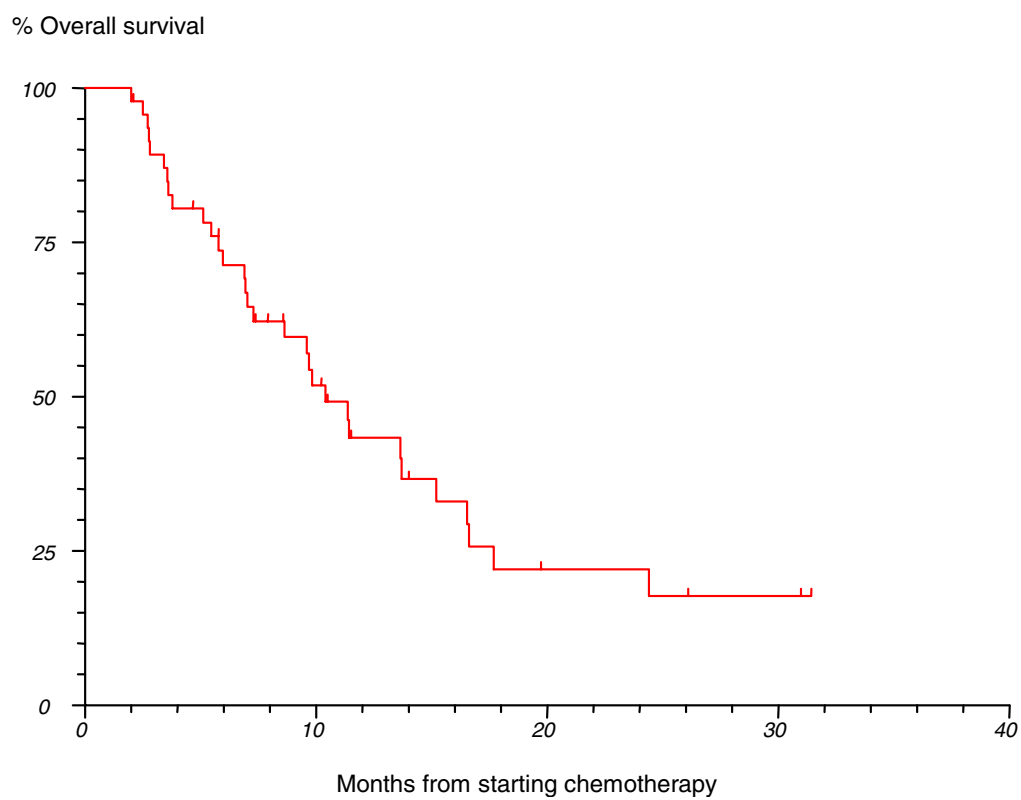

Figure 2

OAS following assay-directed chemotherapy.

patients respectively) between the two groups. However, when grouped by Index SUM for cisplatin the differences are more marked (58\% and $75 \%$ ORR for Index SUM $>350$ and $<350$ for cisplatin respectively). The majority of patients treated by Meyer et al. [9] had 2 or more prior courses of chemotherapy which is similar to our own figures (72\% two or more prior chemotherapy courses). When analysed on an ITT basis the series treated by Meyer et al. [9] have an ORR of 36\%, a PFS of 3.7 months and an OAS of 6.6 months. Our group have shown a greater response rate and longer median survival times (ORR 59\%, PFS 6.6 months, OAS 10.4 months).

At first sight, the clinical definition of platinum resistance does not appear to match the number of patients showing cisplatin resistance on the basis of Index SUM in the ATPTCA. However, most patients in this study had been rechallenged with a second line platinum agent/combina- tion and the assay taken before third-line therapy (or later) shows the expected increase in the cisplatin Index SUM due to acquired resistance. By the time patients presented for ATP-TCA directed therapy $72 \%$ were platinum resistant according to the assay (cisplatin Index SUM>350). Previous studies have shown a negative predictive value of the order of $90 \%$ for resistance to cisplatin in the assay [16].

Most patients in this study were treated with combination therapy, often with experimental protocols. These combinations were previously developed on the basis of assay results and have known clinical efficacy [40,41]. Those chosen for individual patients often differed due to the wide heterogeneity of chemosensitivity exhibited in ovarian epithelial cancer $[13,14,16]$. The ATP-TCA not infrequently suggests potential benefit from drug regimens that may be far from the physician's first choice. Treosul- 


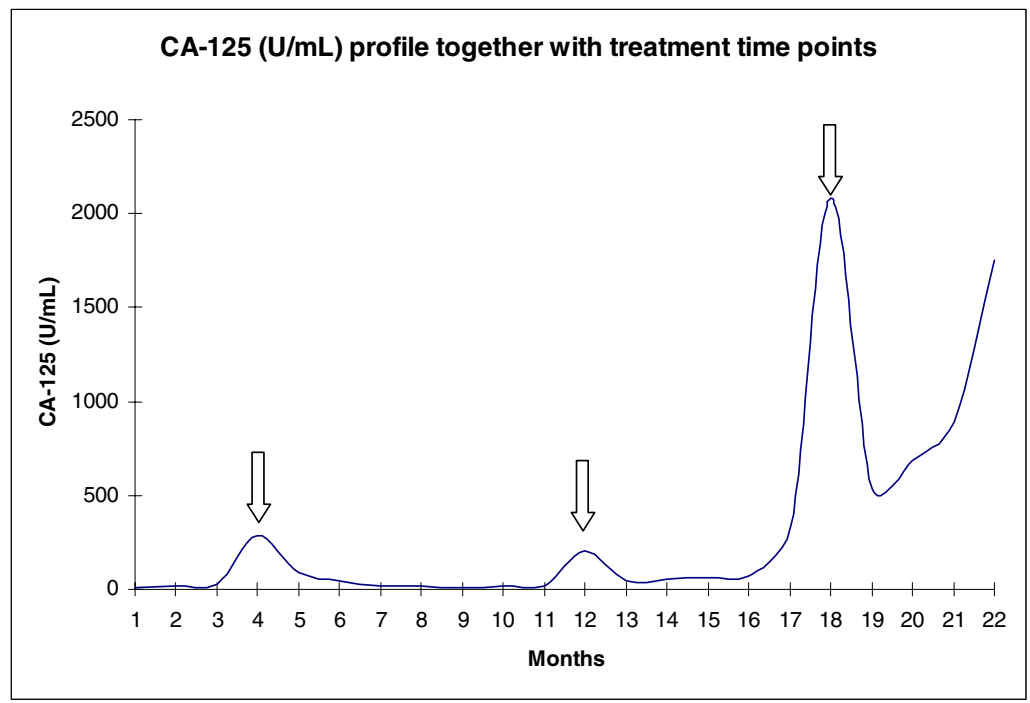

\section{Figure 3}

CA- 125 profile for a patient with 3 successive courses of assay directed therapy

fan + gemcitabine is a new regimen with a good toxicity profile, initially developed for melanoma [42,43], which has been shown to have considerable activity against ovarian cancer in a recent study $[44,45]$. In this series, treosulfan and gemcitabine was used 23 times (41\%) and achieved an ORR of 55\%. Of patients evaluable for response, thirteen patients receiving this combination were resistant to cisplatin in the assay (cisplatin Index SUM > 350) and the ORR in this group was $62 \%$. Six patients were predicted as platinum-sensitive (cisplatin Index SUM < 350), and half of these responded to treosulfan and gemcitabine. The remaining three patients received treosulfan and gemcitabine, but cisplatin was not tested in the assay. Other combinations used in the assay varied widely in their mechanism of action: many involved anthracyclines and some used paclitaxel (Table 2 ). There was reluctance amongst the oncologists involved in this study to re-use paclitaxel, though recent results with the ATP-TCA suggest that resistance to this agent develops less commonly than to platinum [40]. Kaern et al. [46] studied taxane rechallenge after platinum/paclitaxel therapy and found that the likelihood to respond to second-line paclitaxel is largely unaffected by the prior progression free interval.

Figure 3 shows a profile of the CA-125 levels of a patient treated with 3 successive courses of assay directed therapy. This patient was clinically platinum resistant after having been treated with CAP (cyclophosphamide, doxorubicin and cisplatin) four months prior to the start time point of the graph. Sequential ATP-TCA assays recommended cisplatin and gemcitabine; Liposomal doxorubicin; Mitoxantrone and paclitaxel respectively. The arrows show when each treatment was started. These achieved 3 sequential partial responses in the patient with significant drops in the CA-125 counts. A fourth assay recommended 
treosulfan and gemcitabine, but the patient deteriorated rapidly after 2 cycles and died soon after. Nevertheless, this patient survived 18 months after diagnosis of platinum-resistant recurrent ovarian cancer. This example shows how the assay can be use to assist the choice of chemotherapy on multiple occasions during the course of an individual patient's illness.

The use of predictive assays to individualize chemotherapy has been hampered by technical difficulties and (initially) by the availability of drugs with differing mechanisms of action. The increasing number of drugs now available has widened the choice of agents and possible combinations considerably. The ATP-TCA is a wellstandardised assay with established external quality control procedures capable of handling most endoscopic or needle biopsies that compares favourably with other clonogenic and non-clonogenic methods $[13,14,47,48]$.

\section{Conclusions}

In conclusion, the ATP-TCA assay shows favourable response rates when used as a predictive assay to individualize chemotherapy in heavily pre-treated recurrent epithelial ovarian cancer. These results compare well with published second-line therapy results and support previous work using the ATP-TCA in a different country. A multi-centre, randomised trial of ATP-TCA directed therapy versus physician's choice therapy is in progress to help clarify the role of predictive chemosensitivity testing in recurrent ovarian cancer.

\section{Competing Interests}

This work was supported by grants from Schering-Plough (UK) Ltd, Xenova Ltd, Cantech Ltd, the Biology and Biotechnology Science Research Council, and the European Commission. IAC is a director of Cantech Ltd.

\section{Authors' Contributions}

SS completed clinical follow-up and drafted the manuscript. MHN, FDN, LAK, PAW, SJM carried out the ATPTCA assays. BRH provided statistical input. AL, $\mathrm{RO}, \mathrm{ACH}$ recruited and treated patients. CMK and IAC conceived the study and participated in its design and coordination.

\section{Acknowledgements}

We are indebted to Amanda Brookman at King Edward VII Hospital, Midhurst and the Wellcome Trust International Travel Award Scheme. We also thank Peggy Hurworth, Marilyn Phillips, Claire Balmer and Natalie Tidy for their assistance with data collection.

\section{References}

I. Greenlee Robert T., Hill-Harmon Mary Beth, Murray Taylor and Thun Michael: Cancer Statistics, 200 I CA Cancer J Clin 200 I, 5 I: I536.

2. McGuire WP, Hoskins WJ, Brady MF, Kucera PR, Partridge EE, Look KY, Clarke-Pearson DL and Davidson M: Cyclophosphamide and cisplatin compared with paclitaxel and cisplatin in patients with stage III and stage IV ovarian cancer N Engl J Med I996, 334: $1-6$.

3. Piccart MJ, Bertelsen K, James K, Cassidy J, Mangioni C, Simonsen E, Stuart G, Kaye S, Vergote I, Blom R, Grimshaw R, Atkinson RJ, Swenerton KD, Trope C, Nardi M, Kaern J, Tumolo S, Timmers P, Roy JA, Lhoas F, Lindvall B, Bacon M, Birt A, Andersen JE, Zee B, Paul J, Baron $B$ and Pecorelli S: Randomized intergroup trial of cisplatinpaclitaxel versus cisplatin-cyclophosphamide in women with advanced epithelial ovarian cancer: three-year results J Natl Cancer Inst 2000, 92:699-708.

4. Gore ME, Fryatt I, Wiltshaw E and Dawson T: Treatment of relapsed carcinoma of the ovary with cisplatin or carboplatin following initial treatment with these compounds Gynecol Oncol 1990, 36:207-2II.

5. Thigpen JT, Blessing JA, Ball H, Hummel SJ and Barrett RJ: Phase II trial of paclitaxel in patients with progressive ovarian carcinoma after platinum-based chemotherapy: a Gynecologic Oncology Group study J Clin Oncol 1994, 12:1748-1753.

6. Blackledge G, Lawton F, Redman $C$ and Kelly K: Response of patients in phase II studies of chemotherapy in ovarian cancer: implications for patient treatment and the design of phase II trials Br J Cancer 1989, 59:650-653.

7. Markman M, Rothman R, Hakes T, Reichman B, Hoskins W, Rubin S, Jones W, Almadrones $L$ and Lewis J. L., Jr.: Second-line platinum therapy in patients with ovarian cancer previously treated with cisplatin J Clin Oncol 199I, 9:389-393.

8. Gore Martin: Treatment of relapsed epithelial ovarian cancer American Society of Clinical Oncology: 200I Educational Book Edited by: Michael C Perry. Alexandria VA, American Society of Clinical Oncology; 200I:468-476.

9. Meyer T, Nelstrop AE, Mahmoudi M and Rustin GJ: Weekly cisplatin and oral etoposide as treatment for relapsed epithelial ovarian cancer Ann Oncol 200I, I 2: 1705-1709.

10. van der Burg ME, de Wit R, van Putten WL, Logmans A, Kruit WH, Stoter $\mathrm{G}$ and Verweij J: Weekly cisplatin and daily oral etoposide is highly effective in platinum pretreated ovarian cancer BrJ Cancer 2002, 86:19-25.

II. Von Hoff DD, Sandbach JF, Clark GM, Turner JN, Forseth BF, Piccart $\mathrm{MJ}$, Colombo $\mathrm{N}$ and Muggia FM: Selection of cancer chemotherapy for a patient by an in vitro assay versus a clinician J Natl Cancer Inst 1990, 82: I I0-II6.

12. Von Hoff DD, Kronmal R, Salmon SE, Turner J, Green JB, Bonorris JS, Moorhead EL, Hynes HE, Pugh RE, Belt RJ and et al.: A Southwest Oncology Group study on the use of a human tumor cloning assay for predicting response in patients with ovarian cancer Cancer 1991, 67:20-27.

13. Cree IA and Kurbacher CM: Individualizing chemotherapy for solid tumors--is there any alternative? Anticancer Drugs 1997, 8:54I-548.

14. Andreotti PE, Cree IA, Kurbacher CM, Hartmann DM, Linder D, Harel G, Gleiberman I, Caruso PA, Ricks SH, Untch M and et al.: Chemosensitivity testing of human tumors using a microplate adenosine triphosphate luminescence assay: clinical correlation for cisplatin resistance of ovarian carcinoma Cancer Res 1995, 55:5276-5282.

15. Cree IA, Kurbacher CM, Untch M, Sutherland LA, Hunter EM, Subedi AM, James EA, Dewar JA, Preece PE, Andreotti PE and Bruckner HW: Correlation of the clinical response to chemotherapy in breast cancer with ex vivo chemosensitivity Anticancer Drugs 1996, 7:630-635.

16. Konecny G, Crohns C, Pegram M, Felber M, Lude S, Kurbacher C, Cree IA, Hepp $H$ and Untch M: Correlation of drug response with the ATP tumorchemosensitivity assay in primary FIGO stage III ovarian cancer Gynecol Oncol 2000, 77:258-263.

17. Kurbacher CM, Cree IA, Bruckner HW, Brenne U, Kurbacher JA, Muller K, Ackermann T, Gilster TJ, Wilhelm LM, Engel H, Mallmann PK and Andreotti PE: Use of an ex vivo ATP luminescence assay to direct chemotherapy for recurrent ovarian cancer Anticancer Drugs 1998, 9:51-57.

18. Rustin G], Nelstrop AE, McClean P, Brady MF, McGuire WP, Hoskins WJ, Mitchell $H$ and Lambert HE: Defining response of ovarian carcinoma to initial chemotherapy according to serum CA I25 J Clin Oncol 1996, 14:1545-155I.

19. Therasse P, Arbuck SG, Eisenhauer EA, Wanders J, Kaplan RS, Rubinstein L, Verweij J, Van Glabbeke M, van Oosterom AT, Christian MC and Gwyther SG: New guidelines to evaluate the response to 
treatment in solid tumors. European Organization for Research and Treatment of Cancer, National Cancer Institute of the United States, National Cancer Institute of Canada J Natl Cancer Inst 2000, 92:205-2I6.

20. Markman M and Hoskins W: Responses to salvage chemotherapy in ovarian cancer: a critical need for precise definitions of the treated population J Clin Oncol 1992, 10:5 I3-5I4.

21. Markman M: "Recurrence within 6 months of platinum therapy": an adequate definition of "platinum-refractory" ovarian cancer? Gynecol Oncol 1998, 69:91-92.

22. Hunter EM, Sutherland LA, Cree IA, Dewar JA, Preece PE, Wood RA, Linder D and Andreotti PE: Heterogeneity of chemosensitivity in human breast carcinoma: use of an adenosine triphosphate (ATP) chemiluminescence assay Eur J Surg Oncol 1993, 19:242-249.

23. du Bois A: Treatment of advanced ovarian cancer Eur J Cancer 200I, 37:SI-7.

24. Ettinger DS, Finkelstein DM, Abeloff MD, Skeel RT, Stott PB, Frontiera MS and Bonomi PD: Justification for evaluating new anticancer drugs in selected untreated patients with extensivestage small-cell lung cancer: an Eastern Cooperative Oncology Group randomized study J Natl Cancer Inst 1992, 84:10771084.

25. Markman M, Kennedy A, Webster K, Kulp B, Peterson G and Belinson J: Continued chemosensitivity to cisplatin/carboplatin in ovarian carcinoma despite treatment with multiple prior platinum-based regimens Gynecol Oncol 1997, 65:434-436.

26. Breidenbach M, Rein DT, Mallmann P and Kurbacher CM: Individualized long-term chemotherapy for recurrent ovarian cancer after failing high-dose treatment Anticancer Drugs 2002, 13:173-176.

27. Donovan KA, Greene PG, Shuster JL, Partridge EE and Tucker DC: Treatment preferences in recurrent ovarian cancer Gynecol Oncol 2002, 86:200-2II.

28. Clarke-Pearson DL, Van Le L, Iveson T, Whitney CW, Hanjani P, Kristensen G, Malfetano JH, Beckman RA, Ross GA, Lane SR, DeWitte $\mathrm{MH}$ and Fields SZ: Oral topotecan as single-agent second-line chemotherapy in patients with advanced ovarian cancer J Clin Oncol 200I, 19:3967-3975.

29. Gordon AN, Fleagle JT, Guthrie D, Parkin DE, Gore ME and Lacave AJ: Recurrent epithelial ovarian carcinoma: a randomized phase III study of pegylated liposomal doxorubicin versus topotecan J Clin Oncol 200I, 1 9:33 I2-3322.

30. Gore M, Oza A, Rustin G, Malfetano J, Calvert H, Clarke-Pearson D, Carmichael J, Ross G, Beckman RA and Fields SZ: A randomised trial of oral versus intravenous topotecan in patients with relapsed epithelial ovarian cancer Eur J Cancer 2002, 38:57-63.

31. Gore ME, Levy V, Rustin G, Perren T, Calvert AH, Earl H and Thompson JM: Paclitaxel (Taxol) in relapsed and refractory ovarian cancer: the UK and Eire experience $\mathrm{Br} J$ Cancer 1995, 72:10161019.

32. Hanjani P, Nolte S and Shahin MS: Phase II evaluation of 3-day topotecan with cyclophosphamide in the treatment of recurrent ovarian cancer Gynecol Oncol 2002, 85:278-284.

33. Hensley ML, Hoppe B, Leon L, Sabbatini P, Aghajanian C, Chi D and Spriggs DR: The costs and efficacy of liposomal doxorubicin in platinum-refractory ovarian cancer in heavily pretreated patients Gynecol Oncol 200I, 82:464-469.

34. Rustin G], Nelstrop AE, Crawford M, Ledermann J, Lambert HE, Coleman R, Johnson J, Evans H, Brown S and Oster W: Phase II trial of oral altretamine for relapsed ovarian carcinoma: evaluation of defining response by serum CAI25 J Clin Oncol 1997, I 5: 172-176.

35. Villa A, Parazzini F, Scarfone G, Guarnerio P and Bolis G: Survival and determinants of response to third-line chemotherapy in sensitive recurrent ovarian cancer patients $\mathrm{Br} J$ Cancer 1999, 79:373-374.

36. Lund B, Hansen OP, Theilade K, Hansen M and Neijt JP: Phase II study of gemcitabine $\left(2^{\prime}, 2^{\prime}\right.$-difluorodeoxycytidine) in previously treated ovarian cancer patients I Natl Cancer Inst 1994 86: $1530-1533$

37. Rose PG, Blessing JA, Mayer AR and Homesley HD: Prolonged oral etoposide as second-line therapy for platinum-resistant and platinum-sensitive ovarian carcinoma: a Gynecologic Oncology Group study J Clin Oncol 1998, 16:405-4I0.
38. Harries M and Gore M: Part II: chemotherapy for epithelial ovarian cancer-treatment of recurrent disease Lancet Oncol 2002, 3:537-545.

39. Berek JS, Bertelsen K, du Bois A, Brady MF, Carmichael J, Eisenhauer EA, Gore M, Grenman S, Hamilton TC, Hansen SW, Harper PG, Horvath G, Kaye SB, Luck HJ, Lund B, McGuire WP, Neijt JP, Ozols RF, Parmar MK, Piccart-Gebhart MJ, van Rijswijk R, Rosenberg P, Rustin $\mathrm{GJ}$, Sessa C, Willemse PH and et al.: Advanced epithelial ovarian cancer: 1998 consensus statements Ann Oncol 1999, 10:87-92.

40. Kurbacher CM, Bruckner HW, Cree IA, Kurbacher JA, Wilhelm L, Poch G, Indefrei D, Mallmann P and Andreotti PE: Mitoxantrone combined with paclitaxel as salvage therapy for platinumrefractory ovarian cancer: laboratory study and clinical pilot trial Clin Cancer Res 1997, 3: 1527-1533.

4I. Kurbacher CM Stier U, Janat M, Cree IA, Bruckner HW: ATP-assay directed chemotherapy for recurrent ovarian cancer: Mature results of an ISCO clinical study group trial ASCO Volume 20. Edited by: Steven M Grunberg. San Francisco, CA, American Society of Clinical Oncology; 200I I84b.

42. Myatt N, Cree IA, Kurbacher CM, Foss AJ, Hungerford JL and Plowman PN: The ex vivo chemosensitivity profile of choroidal melanoma Anticancer Drugs 1997, 8:756-762.

43. Neale MH, Myatt N, Cree IA, Kurbacher CM, Foss AJ, Hungerford IL and Plowman PN: Combination chemotherapy for choroidal melanoma: ex vivo sensitivity to treosulfan with gemcitabine or cytosine arabinoside $\mathrm{Br}$ / Cancer 1999, 79: | 487- | 493.

44. Breidenbach M Rein D, Konig P, Bruckner HW, Kurbacher CM: Toxicity profiles of different chemotherapy regimens for recurrent ovarian cancer guided by an ex vivo chemosensitivity assay ASCO Volume 20. Edited by: Steven M Grunberg. San Francisco, CA, American Society of Clinical Oncology; 200II8Ib.

45. Grecu OM Kurbacher CM, Mallmann P, Bruckner HW, Cree IA: Treosulfan and gemcitabine in heavily pretreated patients with breast and ovarian cancer: Laboratory study and clinical pilot trial of the ISCO clinical study group ASCO Volume 20. Edited by: Steven M Grunberg. San Francisco, CA, American Society of Clinical Oncology; 200II 87b.

46. Kaern J Trope CG, Baekelandt M, Kristensen GB: Phase II trial of weekly single agent paclitaxel (P) in platinum (PLAT) and paclitaxel refractory ovarian cancer (OC) ASCO Volume 20. Edited by: Steven M Grunberg. San Francisco, CA, American Society of Clinical Oncology; 200I203a.

47. Cree IA, Pazzagli M, Mini E, Mazzei T, Hunter EM, Sutherland LA, Pinzani P, Gerli A and Andreotti PE: Methotrexate chemosensitivity by ATP luminescence in human leukemia cell lines and in breast cancer primary cultures: comparison of the TCA- 100 assay with a clonogenic assay Anticancer Drugs 1995, 6:398-404.

48. Petty RD, Sutherland LA, Hunter EM and Cree IA: Comparison of MTT and ATP-based assays for the measurement of viable cell number J Biolumin Chemilumin 1995, 10:29-34.

\section{Pre-publication history}

The pre-publication history for this paper can be accessed here:

\section{http://www.biomedcentral.com/1471-2407/3/19/prepub}

Publish with BioMed Central and every scientist can read your work free of charge

"BioMed Central will be the most significant development for disseminating the results of biomedical research in our lifetime. "

Sir Paul Nurse, Cancer Research UK

Your research papers will be:

- available free of charge to the entire biomedical community

- peer reviewed and published immediately upon acceptance

- cited in PubMed and archived on PubMed Central

- yours - you keep the copyright 